\title{
FERTILIZANTE ORGANOMINERAL E ARGILA SILICATADA COMO INDUTORES DE RESISTÊNCIA À VARÍOLA DO MAMOEIRO
}

\section{BIOFERTILIZER AND SILICATE CLAY AS RESISTANCE INDUCTORS TO THE BLACK SPOT OF PAPAYA DISEASE}

\author{
Dirceu Pratissoli ${ }^{1}$; Gustavo Dias de Almeida ${ }^{1}$; Waldir Cintra Jesus Júnior ${ }^{1}$; \\ Victor Bernardo Vicentini ${ }^{1}$; Anderson Mathias Holtz ${ }^{1}$; Juliéder Goronci Cocheto ${ }^{1}$
}

\section{RESUMO}

A varíola ou pinta preta é um dos mais sérios problemas para cultura do mamoeiro e seu controle é baseado na aplicação excessiva de produtos químicos. O objetivo deste trabalho foi avaliar o efeito da aplicação de fertilizante organomineral e argila silicatada na indução de resistência à varíola em plantas de mamão, avaliando-se a incidência e severidade. Os tratamentos receberam aplicações foliares do fertilizante organomineral (T2), argila silicatada (T3), fertilizante organomineral mais argila silicatada (T4) e água na testemunha (T1). As avaliações foram realizadas 5 dias após a $6^{\mathrm{a}}, 9^{\mathrm{a}}$ e $12^{\mathrm{a}}$ aplicação foliar dos produtos. Os tratamentos 2,3 e 4 proporcionaram significativa redução da incidência e severidade da doença. Contudo, maior redução da incidência e severidade foi observada quando se associou fertilizante organomineral mais argila silicatada (T3). A aplicação destes produtos é uma medida eficaz e economicamente viável para o manejo da varíola em cultivos de mamão.

Palavras chave: Asperisporium caricae, Carica papaya, indução de resistência, agricultura sustentável.

\section{ABSTRACT}

Black spot of papaya disease is one of the most serious problems of the papaya culture and its control is based on the excessive application of chemical products. The goal of this study was to evaluate the effect of the application of biofertilizer and silicate clay in the resistance induction to the black spot of papaya disease, being evaluated the incidence and severity. The treatments received road leaf applications of biofertilizer (T2), silicate clay (T3), biofertilizer plus silicate clay and water on the witness (T1). The evaluations were made 5 days after to $6^{\text {th }}, 9^{\text {th }}$ and $12^{\text {th }}$ road leaf application of the products. The treatments 2,3 and 4 provided significant reduction of the disease's incidence and severity. However, the incidence and severity reduction were larger with biofertilizer plus silicate clay associated. The application of these products is a effective measure and economically viable method for the black spot management in papaya cultivations.

Key word: Asperisporium caricae, Carica papaya, induction resistance, sustainable agriculture.

\section{INTRODUÇÃO}

O Brasil é o maior produtor mundial de mamão, com uma produção de 1,5 milhão de tonelada ao ano (Martins \& Costa, 2003). Entretanto, o mamoeiro pode ser afetado por diversas doenças, sendo esse o fator econômico mais importante na redução da produção e exportação de frutos in natura (Nishijima et al., 1994). Dentre as doenças, destaca-se a varíola ou pinta preta, causada por Asperisporium caricae (Speg) Maubl., que devido a alta frequiência que ocorre e danos que pode ocasionar, constitui-se um dos mais sérios problemas na cultura do mamoeiro (Oliveira et al., 2000).

Para contornar tais problemas, o controle dessa doença baseia-se principalmente na aplicação de

1 UFES/CCA, Depto. Produção Vegetal, Núcleo de desenvolvimento em manejo fitossanitário (Nudemafi), Alto Universitário, Alegre-ES, Brasil; C. postal 16, CEP. 29.500,000; E-mail: gustavo.ccaufes@ hotmail.com

Fecha de Recepción: 18 Abril 2007

Fecha de Aceptación: 07 Mayo 2007 
fungicidas (Rezende et al., 2005). Contudo, o uso intensivo destes fungicidas pode provocar resistência do patógeno aos mesmos, bem como afetar a saúde humana, tanto do consumidor, como a dos profissionais envolvidos nos processos de produção e provocar efeitos negativos sobre o meio ambiente (Tuzun \& Kuc, 1991).

Objetivando alternativas ao controle químico, o emprego da resistência genética tem sido uma das práticas mais eficientes dentro do manejo integrado (Torres \& Garcia, 1996). No entanto, um programa de melhoramento genético é oneroso e demorado, nem sempre respondendo rapidamente à necessidade da agricultura (Cavalcanti et al., 2005). Contudo, uma alternativa de fácil manejo e baixo custo é a resistência induzida, que consiste no aumento do nível de resistência da planta por meio da utilização de agentes externos (indutores), sem qualquer alteração do genoma da planta (Stadnik, 2000).

O silício tem sido relatado como um dos elementos associados à indução da resistência em plantas (Savant et al., 1999) e sua absorção pode trazer aumento dessa resistência, principalmente para culturas que o acumulam (Mauad et al., 2003). Pesquisas realizadas com diversas culturas confirmaram o potencial do silício na redução da intensidade e severidade de doenças (Menzies et al., 1991; Datnoff et al., 1997). Plantas de arroz (Oryza sativa L.), por exemplo, cultivadas com doses crescentes desse elemento tiveram a severidade da queima-das-bainhas (Rhizoctonia solani Kühn) reduzida (Rodrigues et al., 2002). No entanto, para o mamoeiro os efeitos do silício sobre as doenças ainda não foram testadas.

O mecanismo pelo qual o silício afeta o desenvolvimento das doenças em plantas é possivelmente resultado da ação deste elemento no tecido do hospedeiro, proporcionando impedimento físico e um maior acúmulo de compostos fenólicos e lignina no local da injúria (Chérif et al., 1992). Esta função estrutural proporciona mudanças anatômicas nos tecidos, como células epidérmicas com a parede celular mais espessa devido à deposição de sílica nas mesmas (Blaich \& Grundh Fer, 1998), favorecendo a melhor arquitetura das plantas, além de aumentar a capacidade fotossintética e resistência às doenças (Bélanger \& Menzies, 2003).

Dentre as fontes de silício, o silicato de cálcio $\left(\mathrm{CaSiO}_{3}\right)$ é a forma mais empregada na maioria dos produtos comerciais (Barbosa Filho et al., 2000). Entre os produtos comercializados têm-se a argila silicatada, cujo, nome comercial é Rocksil ${ }^{\circledR}$. Um outro exemplo de produto comercial é o fertilizante organomineral, cujo nome comercial é Ergofito ${ }^{\circledR}$, que atua proporcionando uma rápida assimilação de nutrientes disponíveis, aumentando a produção de massa vegetal, fato que pode tornar a planta resistente a patógenos (Tecnobiol, 2005).

Desta forma, o objetivo do presente trabalho foi avaliar o efeito do uso do fertilizante organomineral e argila silicatada, isolados ou associados, na redução da incidência e severidade de $A$. caricae em mamoeiro.

\section{MATERIAL E MÉTODOS}

O experimento foi realizado no Núcleo de Desenvolvimento Científico e Tecnológico em Manejo Fitossanitário de Pragas e Doenças (NUDEMAFI) do Centro de Ciências Agrárias da Universidade Federal do Espírito Santo (CCAUFES), em Alegre - ES. Plantas de mamão (Carica papaya) var. formosa foram cultivadas em sacolas plásticas $(16 \mathrm{~cm} \times 34 \mathrm{~cm})$ e mantidas em condições de campo. A aplicação do fertilizante organomineral e argila silicatada, iniciaram-se 60 dias após a semeadura, sendo realizada a intervalos de 10 dias. As aplicações foram realizadas via foliar, com auxílio de um mini-pulverizador manual. As pulverizações com fertilizante organomineral foram a base de 2,0 $\mathrm{ml} / \mathrm{L}$ de água, argila silicatada a $15,0 \mathrm{~g} / \mathrm{L}$ de água e na associação dos produtos, utilizou-se $2,0 \mathrm{~mL}$ do fertilizante organomineral por litro de água mais $4,0 \mathrm{~g}$ de argila silicatada por litro de água. Como testemunha foi utilizado água nas pulverizações das plantas.

As quantificações de incidência e severidade foram realizadas cinco dias após a $6^{\mathrm{a}}, 9^{\mathrm{a}}$ e $12^{\mathrm{a}}$ aplicação dos produtos. A incidência foi expressa em porcentagem, sendo esta obtida através da contagem do número de folhas que apresentaram sintomas da doença, dividido pelo número total de folhas de cada planta e multiplicado por cem. A severidade da doença foi quantificada retirando-se duas folhas com a mesma idade fisiologica, na parte inferior de cada planta, as quais foram escaneadas e submetidas ao programa QUANT (1.0.1) (Vale et al., 2004), obtendo-se a área lesionada de cada folha.

$\mathrm{O}$ experimento foi conduzido empregando-se um delineamento inteiramente casualizado com fatorial em parcela subdividida $3 \times 4$, sendo um 
fator o número de aplicações e o outro a fonte de indução. Foram realizadas 4 repetições por tratamento, sendo cadê repetição constituída por uma planta de mamão. As médias foram comparadas pelo teste de Tukey a 5\% de probabilidade, através do Software SAEG 9.0.

\section{RESULTADOS E DISCUSSÃO}

Foram observadas interações significativas entre os tratamentos e número de aplicações, para incidência e severidade de lesões causadas por $A$. caricae.

A utilização do fertilizante organomineral e argila silicatada proporcionaram menor incidência de lesões causadas por A. caricae nas folhas das plantas de mamão em relação à testemunha, destacando-se o tratamento em que se utilizou a associação dos dois produtos, o qual apresentou menor incidência em todas as aplicações (Tabela 1). Vale ressaltar que, não foram observados valores de incidência menores que 50\%. Assim, para tentar diferenciar os tratamentos também utilizou-se os dados de severidade. A partir dessa análise, verificou-se que os tratamentos que receberam aplicação de fertilizante organomineral e argila silicatada, a severidade da doença foi significativamente menor (Tabela 2). Porém, a menor área abaixo da curva de progresso da severidade da doença (AACPD) foi observada no tratamento que recebeu aplicação de fertilizante organomineral mais argila silicatada associados (Tabela 2, Figura 1).

Resultados semelhantes foram observados por Santos (2002), que constatou um decréscimo linear na incidência e severidade da cercosporiose com a utilização de silicatos de cálcio e sódio nos substratos de mudas de café.

Possivelmente, os mecanismos pelos quais o silício pode conferir resistência à determinada doença podem ser por barreiras estruturais como o acúmulo desse elemento na parede das células da epiderme e da cutícula ou acúmulo no local de penetração do patógeno (Rodrigues et al., 2003),

\section{Tabela 1}

Incidência da varíola do mamoeiro (A. caricae) em folhas de mamão (Carica papaya) tratadas com fertilizante organomineral e argila silicatada

\begin{tabular}{|c|cccc|}
\hline Tratamento & \multirow{2}{*}{$\begin{array}{c}\text { Fertilizante } \\
\text { organomineral }\end{array}$} & Argila Silicatada & $\begin{array}{c}\text { Fert. organomineral } \\
\text { + Argila silicatada }\end{array}$ & Testemunha \\
\cline { 1 - 4 } Aplicações & $68,55 \pm 3,72 \mathrm{Aa}$ & $62,41 \pm 1,58 \mathrm{Aa}$ & $62,30 \pm 2,44 \mathrm{Aab}$ & $87,25 \pm 3,11 \mathrm{Ba}$ \\
\hline 6 & $85,45 \pm 1,20 \mathrm{BCb}$ & $78,30 \pm 2,77 \mathrm{Bb}$ & $56,39 \pm 3,08 \mathrm{Aa}$ & $89,15 \pm 3,70 \mathrm{Ca}$ \\
\hline 9 & $80,42 \pm 1,04 \mathrm{Bb}$ & $78,45 \pm 1,74 \mathrm{ABb}$ & $69,00 \pm 0,82 \mathrm{Ab}$ & $95,01 \pm 1,73 \mathrm{Ca}$ \\
\hline 12 &
\end{tabular}

Médias seguidas por uma mesma letra maiúscula nas linhas, e minúscula nas colunas, não diferem entre si pelo teste Tukey, a $5 \%$ de probabilidade.

Tabela 2

Severidade da varíola do mamoeiro (A. caricae) em folhas de mamão (Carica papaya) tratadas com fertilizante organomineral e argila silicatada

\begin{tabular}{|c|cccc|}
\hline Tratamentos & \multirow{2}{*}{$\begin{array}{c}\text { Fertilizante } \\
\text { organomineral }\end{array}$} & Argila Silicatada & $\begin{array}{c}\text { Fert. Organomineral } \\
\text { + Arg. Silicatada }\end{array}$ & Testemunha \\
\cline { 1 - 4 } Aplicações & $4,30 \pm 0,54 \mathrm{Ba}$ & $2,82 \pm 0,42 \mathrm{ABa}$ & $2,21 \pm 0,29 \mathrm{Aa}$ & $16,70 \pm 0,94 \mathrm{Ca}$ \\
\hline 6 & $6,82 \pm 0,59 \mathrm{Bb}$ & $3,27 \pm 0,31 \mathrm{Aab}$ & $3,07 \pm 0,32 \mathrm{Aa}$ & $18,43 \pm 1,45 \mathrm{Cb}$ \\
\hline 9 & $4,65 \pm 0,52 \mathrm{Aa}$ & $4,79 \pm 0,36 \mathrm{Ab}$ & $3,77 \pm 0,25 \mathrm{Aa}$ & $20,24 \pm 1,37 \mathrm{Bc}$ \\
\hline
\end{tabular}

Médias seguidas por uma mesma letra maiúscula nas linhas, e minúscula nas colunas, não diferem entre si pelo teste Tukey, a 5\% de probabilidade. 


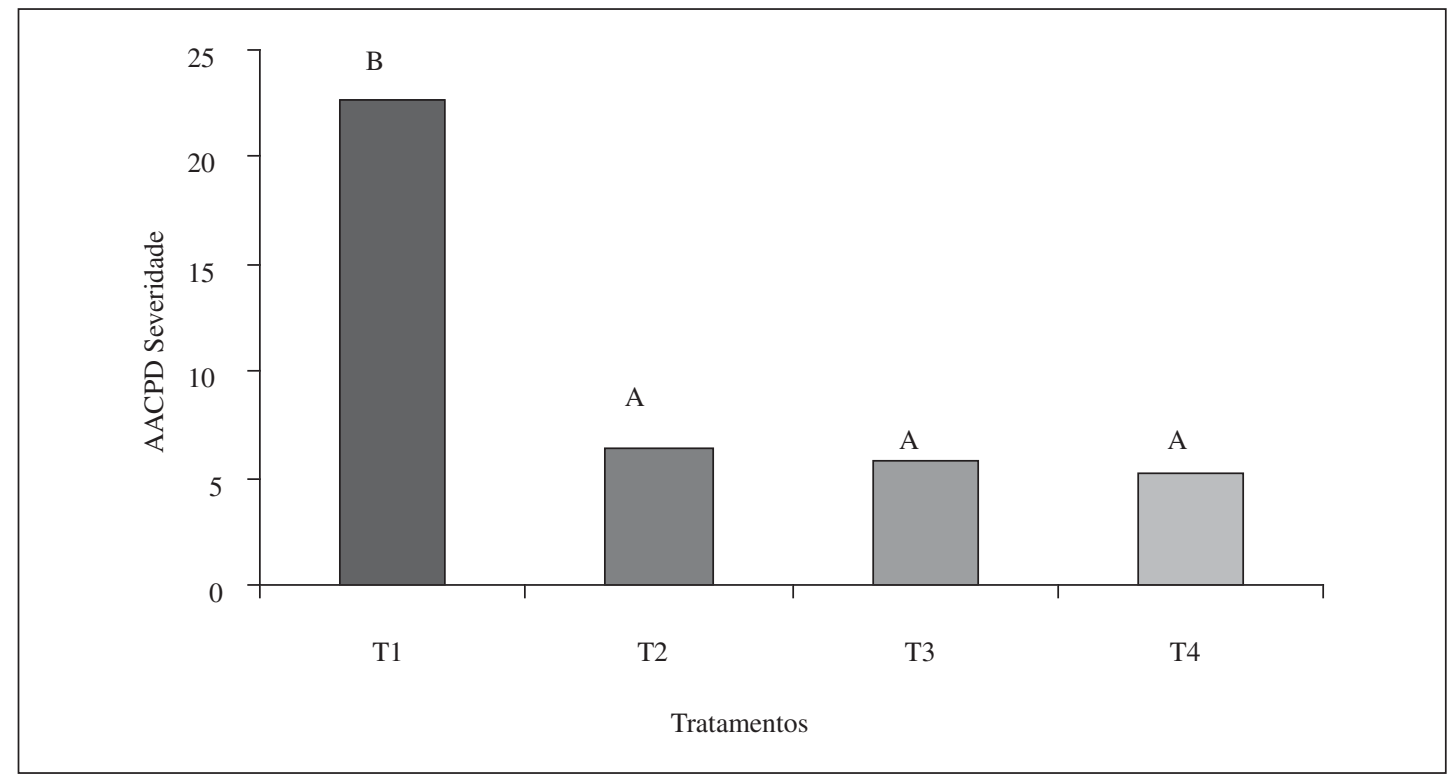

Figura 1. Área abaixo da curva de progresso da severidade da varíola (A. caricae) em função dos tratamentos, (T1) testemunha; (T2) Fertilizante organomineral; (T3) Argila Silicatada; (T4) Fertilizante Organomineral + Argila Silicatada.

ou por ativar barreiras químicas e bioquímicas das plantas (Bélanger et al., 2003). Nesse mesmo sentido, Pozza et al., (2004) observaram que o aumento da resistência do cafeeiro à cercosporiose foi devido ao maior espessamento da cutícula e ao aumento da absorção de micronutrientes pelas plantas tratadas com silício. Essa hipótese foi constatada através de imagens em microscopia eletrônica de varredura, nas quais observaram a presença de uma cutícula mais espessa cobrindo parcialmente os estômatos na superfície inferior da folha das mudas de cafeeiro tratadas com silicato de cálcio no solo. Os autores observaram que o espessamento da cutícula, devido principalmente à formação de uma camada de cera epicuticular mais espessa, dificultou a penetração do patógeno diretamente através da cutícula ou pelos estômatos. Essa camada de cera epicuticular pode ter tornado a superfície mais hidrofóbica, impedindo a formação do filme de água, importante para os processos vitais de patogênese, como a germinação e a penetração, além de permitir o acúmulo de substâncias antifúngicas na cutícula (Pascholati \& Leite, 1995).

Ao final das avaliações nota-se que a (AACPD) da severidade na testemunha foi significativamente maior do que nos demais tratamentos. No entanto, no tratamento em que se associou fertilizante organomineral mais argila silicatada observou-se a menor (AACPD) (Figura 1). Dessa forma, a associação do fertilizante organomineral mais argila silicatada pode ser considerada como uma alternativa viável dentro da produção integrada do mamoeiro.

Contudo, para se obter bons resultados do efeito de fontes silicatadas no aumento da resistência de plantas a patógenos, é necessário suprimento contínuo desses elementos (Bélanger \& Menzies, 2003). Sendo assim, para se reduzir a severidade da varíola do mamoeiro deve-se manter uma periodicidade das aplicações, juntamente com outras alternativas viáveis de controle, que permitam a sustentabilidade do agroecossistema envolvido.

\section{CONCLUSÃO}

A aplicação foliar de fertilizante organomineral a $0,5 \%$, argila silicatada a $1,5 \%$ e a associação do fertilizante organomineral a $0,5 \%$ com argila silicatada a $0,4 \%$ diluídos em água, reduz a incidência e principalmente a severidade da varíola do mamoeiro (A. caricae), mostrando-se potencial para o manejo da resistência do mamoeiro a este patógeno. 


\section{REFERÊNCIAS BIBLIOGRAFICAS}

BARBOSA FILHO, M.P.; SNYDER, G.H.; PRABHU, A.S.; DATNOFF, L.E.; KORNDORFER, G.H. 2000. Importância do silício para a cultura do arroz: uma revisão de literatura. Piracicaba. Informações agronômicas, v.89, 11 p.

BÉLANGER, R.R.; BENHAMOU, N.; MENZIES, J.G. 2003. Mineral nutrition in the management of plant diseases. Phytopathology, v.93, p. 402-412.

BÉLANGER, R.R.; MENZIES, J.G. 2003. Use of silicon to control diseases in vegetable crops. In: XXXVI CONGRESSO BRASILEIRO DE FITOPATOLOGIA, Uberlândia. Anais da Sociedade Brasileira de Fitopatologia, v.36, p. S42-S45.

BLAICH, R; GRUNDHÖFER, H. 1998. Silicate incrusts induced by powdery mildew in cell walls of diferent plant species. Zeitschift fur Pflanzenkrankheiten und Pflanzenschutz, v.105, p. 114-120.

CAVALCANTI, L.S.; PIERO, R.M.; CIA, P.; PASCHOALATI, S.F.; RESENDE, M.L.V.; ROMEIRO, R.S. 2005. Indução de resistência a patógenos e insetos. Piracicaba: FEALQ. $263 \mathrm{p}$.

CHÉRIF, M.; MENZIES, J.G.; BENHAMOU,N.; BÉLANGER, R.R. 1992. Studies of silicon distribution in wounded and Pythium ultimum infected cucumber plants. Physiological and Molecular Plant Pathology, v.41, p. 371-385.

DATNOFF, L.E., DEREN, C.W.; SNYDER, G.H. 1997. Silicon fertilization for disease management of rice in Florida. Crop Protection, v.16, p. 525-531.

MARTINS, D.S.; COSTA, A.F. 2003. A cultura do mamoeiro: Tecnologias de Produção. Vitória: Incaper, 497 p.

MENZIES, J.G.; EHRET, D.L.; GLASS, A.D.M.; HELMER, T.; KOCH, C.; SEYWERD, F. 1991. Effects of soluble silicon on the parasitic fitness of Sphaerotheca fuliginea on Cucumis sativus. Phytopathology, v.81, p. 84-88.

MAUAD, M.; GRASSI FILHO, H.; CRUSCIOL, C.A.C.; CORREAA, J.C. 2003. Teores de silício no solo e na planta de arroz de terras altas com diferentes doses de adubação silicatada e nitrogenada. Revista Brasileira de Ciência do Solo, v.27, p. 867-873.

NISHIJIMA, W.T.; DICKMAN, M.B.; KO, W.H.; OOKA, J.J. 1994. Papaya diseases caused by fungi. In: PLOEZ, R.C.; ZENTMYER, G.A.; NISHIJIMA, W.T.; ROHRBACH, K.G.; OHR, H.D. (Ed). Compendium of tropical fruit diseases. St. Paul, MN: American Phytopathological Society, p. 58-64.

OLIVEIRA, A.A.R.; SANTOS FILHO, H.P. 2000. Doenças. In: RITZINGER, C.H.S.P.; SOUZA, J.S. (Ed). Mamão: fitossanidade. Brasília: Embrapa Comunicação para Transferência de Tecnologia, p. 37-46.
PASCHOLATI, S.F.; LEITE, B. 1995. Hospedeiro: mecanismo de resistência. In: BERGAMIN FILHO, A.; KIMATI, H.; AMORIM, L. (Ed.). Manual de fitopatologia-Princípios e conceitos. São Paulo, p. 417-454.

POZZA, A.A.A.; ALVES, E.; POZZA, E.A.; CARVALHO, J.G.; MONTANARI, M.; GUIMARÃES, P.T.G.; SANTOS, D.M. 2004. Efeito do silício no controle da cercosporiose em três variedades de cafeeiro. Fitopatologia Brasileira, v.29, p. 185-188.

REZENDE, J.A.M.; MARTINS, M.C. 2005. Doenças do mamoeiro. In: KIMATI, H., AMORIM, L.; REZENDE, J.A.M.; BERGAMIM FILHO, A.; CAMARGO, L.E.A. (Ed) Manual de Fitopatologia. Doença das plantas cultivadas. São Paulo: v. 2, p. 435-443.

RODRIGUES, F.A.; VALE, F.X.R.; KORNDÖRFER, G.H.; PRABHU, A.; DATNOFF, L.E.; OLIVEIRA, A.M.A.; ZAMBOLIM, L. 2002. Influence of silicon on sheath blight of rice in Brasil. Crop Protection, v.22, p. 23-29.

RODRIGUES, F.A.; BENHAMOU, N.; DATNOFF, L.E.; JONES, J.B.; BÉLANGER, R.R. 2003. Ultrastuctural and cytochemical aspects of silicon-mediated rice blast resistance. Phytopathology, v.93, p. 535-546.

SANTOS, D.M. 2002. Efeito do silício na intensidade da cercosporiose Cercospora coffeicola (Berk. \& Cooke) em mudas de cafeeiro (Coffea arabica L.). Tese (Mestrado) -Universidade Federal de Lavras, Lavras -MG, 43 p.

SAVANT, N.K.; KORNDORFER, G.H.; DATNOFF, L.E.; SNYDER, G.H. 1999. Silicon nutrition and sugarcane production: a review. Journal of Plant Nutrition, v.22, p. 1853-1903.

STADNIK, M. 2000. Indução de resistência a oídios. In: CONGRESSO PAULISTA DE FITOPATOLOGIA, Campinas. Anais do Congresso Paulista de Fitopatologia, v. 23 , p. 176-181.

TORRES, E.; GARCIA, C. 1996. Realidades y perspectivas del fenómeno de la resistencia inducida de plantas a fitopatógenos. Bogotá: Universidad Nacional de Colombia. p. 16.

TECNOBIOL S.A. FERTILIZANTES DO BRASIL. 2005. Departamento Técnico/Comercial. Boletim Técnico Ergofito. 5 p.

TUZUN, S.; KUC, J. 1991. Plant immunization: an alternative to pesticides for control of plant diseases in the greenhouse and field. Technical Bulletin-Food and Fertilizer Technology Center, v.124, 11 p.

VALE, F.X.R.; JESUS Jr, W.C.; LIBERATO, J.R. SOUZA, C.A. 2004. Quantificação de doença e do crescimento do hospedeiro. In: VALE, F.X.R.; JESUS Jr, W.C.; ZAMBOLIM, L. Epidemiologia aplicada ao manejo de doenças de plantas, p. 89-124. 